\title{
A Importância da Atuação Odontológica em Pacientes Internados em Unidade de Terapia Intensiva*
}

\section{Importance of Dental Work in Patients under Intensive Care Unit}

\author{
Teresa Márcia Nascimento de Morais ${ }^{1}$, Antonio da Silva², Ana Luiza Ribeiro de Oliveira Avi ${ }^{3}$, \\ Patrícia Helena Rodrigues de Souza ${ }^{4}$, Elias Knobel ${ }^{5}$, Luiz Fernando Aranha Camargo ${ }^{6}$.
}

\section{RESUMO}

JUSTIFICATIVA E OBJETIVOS: Em unidade de terapia intensiva (UTI), a pneumonia nosocomial é responsável por altas taxas de morbidade, mortalidade e aumento expressivo dos custos hospitalares, sendo que seu estabelecimento se dá mais comumente pela aspiração do conteúdo presente na boca e faringe. O objetivo deste estudo foi buscar dados na literatura sobre a participação da condição bucal no estabelecimento da pneumonia nosocomial.

CONTEÚDO: A higiene bucal deficiente é comum em pacientes internados em UTI, o que propicia a colonização do biofilme bucal por microrganismos patogênicos, especialmente por patógenos respiratórios. Os estudos mostram claramente que a quantidade de biofilme bucal em pacientes de UTI aumenta com o tempo

1. Mestre pela USP; Coordenadora do Departamento de Odontologia da Santa Casa de Misericórdia de Barretos; Especialista em Periodontia pela FEB

2. Médico Graduado pela PUCSP; Especialista em Cardiologia pela SBC e PUCSP

3. Cirurgiã-Dentista da Fundação Pio XII - Hospital do Câncer de Barretos e da Santa Casa de Misericórdia de Barretos; Especialista em Periodontia pela FEB

4. Mestre e Doutora pela UNESP, Diretora Geral da FEB; Coordenadora do Curso de Especialização em Periodontia da FEB

5. Diretor Emérito e Fundador do Centro de Terapia Intensiva do Hospital Israelita Albert Einstein; Vice-Presidente de Prática Médica da SBIBAE

6. Gerente Médico da Unidade Clínico-Cirúrgica do Hospital Israelita Albert Einstein

Apresentado em 01 de agosto de 2006

Aceito para publicação em 28 de novembro de 2006

Endereço para correspondência:

Dra. Teresa Márcia Nascimento de Morais

Av. $25, \mathrm{n}^{\circ} 1.246$

14780-330 Barretos, SP

Fones: (17) 3325-8552 / 3323-5435

E-mail: teresamorais@uol.com.br

(C)Associação de Medicina Intensiva Brasileira, 2006 de internação, paralelamente também ocorre aumento de patógenos respiratórios que colonizam o biofilme bucal, sendo esse um reservatório importante de patógenos.

CONCLUSÕES: Apesar de hipóteses bem fundamentadas que estreitam as relações entre infecções pulmonares e a condição bucal, os estudos ainda não estão completamente definidos. Diante de fortes possibilidades de que estas hipóteses sejam verdadeiras, se faz necessário à aquisição e manutenção da saúde bucal, além de maior integração da Odontologia e da Medicina, visando o tratamento global dos pacientes, a prevenção de doenças e maior humanização dos pacientes internados em UTI.

Unitermos: Higiene bucal, Pneumonia, UTI

\section{SUMMARY}

BACKGROUND AND OBJECTIVES: In the intensive care unit, the nosocomial respiratory infection is responsible for high rates of morbidity, mortality and expressive increase in hospitals costs. Its establishment feels more commonly by the aspiration of the content present within the mouth and the pharynx. Thus we intended to review the literature on the participation of the oral condition in the establishment of the nosocomial respiratory infection.

CONTENTS: Deficient oral hygiene is common in patients under intensive care, which provides the colonization of oral biofilm for pathogenic microorganisms, especially for respiratory pathogens. The studies clearly show that the amount of oral biofilm in patients under intensive care increases according to period hospitalization meanwhile there also is an increase in respiratory pathogens. That colonizes the oral biofilm. This biofilm is an important resource of pathogens in patients under intensive care.

CONCLUSIONS: In spite of well-established hypotheses that narrow down the relationships between lung 
infections and the oral condition, the studies are not still completely defined. However, due to strong possibilities that these hypotheses are true, it is necessary to have and maintain the oral health, in addition to more integration of dentistry and of Medicine, seeking patients' global treatment, the prevention of diseases, and more humanization at the intensive care unit.

Key Words: ICU, Oral hygiene, Pneumonia

\section{INTRODUÇÃO}

Há muito se suspeita da relação de doenças bucais e sistêmicas sendo as primeiras citações científicas desta relação datada em 2.100 a.C. ${ }^{1}$. Desde então, muito se tem estudado e inúmeras pesquisas vêm se desenvolvendo com os resultados evidenciando cada vez mais esta possível relação ${ }^{1}$. Indicando que problemas bucais, especialmente a doença periodontal, podem atuar como foco de disseminação de microrganismos patogênicos com efeito metastático sistêmico, especialmente em pessoas com a saúde comprometida ${ }^{1-5}$. Os avanços científicos trazem subsídios para acreditar na contribuição significativa do tratamento odontológico, especificamente a intervenção periodontal, na prevenção e/ou melhora da condição sistêmica, principalmente no paciente crítico $0^{6,7}$.

O objetivo deste estudo foi buscar dados na literatura sobre a participação da condição bucal no estabelecimento da pneumonia nosocomial de pacientes internados em UTI.

\section{DOENÇA PERIODONTAL}

A doença periodontal é, hoje, reconhecida como doença de origem infecciosa e de natureza inflamatória, que envolve a destruição dos tecidos de suporte do dente por meio da ação direta de bactérias e de seus produtos, ou por ação indireta, onde as reações de destruição tecidual são mediadas pelo hospedeiro ${ }^{3}$ (Figura 1).

As bactérias envolvidas com a doença periodontal são espécies Gram-negativas representadas por:

- Actinobacillus actinomycetemcomitans - Capacidade de invadir células epiteliais bucais e células endoteliais vasculares humanas. Além de induzir a morte celular por apoptose ${ }^{8}$;

- Porphyromonas gingivalis - Capaz de invadir células epiteliais e células endoteliais humanas e potencial para colaborar com fenômenos de agregação plaquetária和;

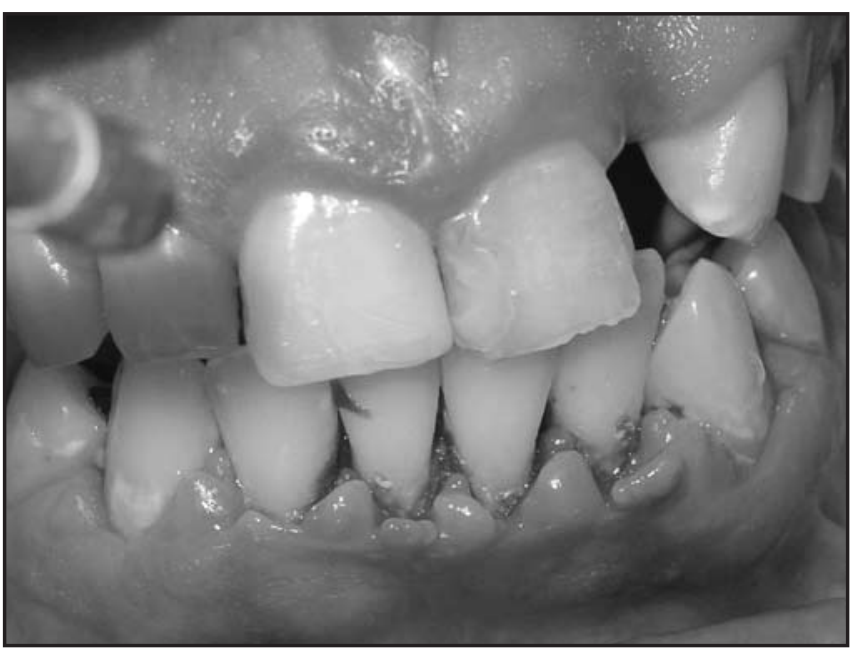

Figura 1 - Aparência Clínica de Paciente Portador de Doença Periodontal Avançada.

Note a presença dos diferentes sinais da doença periodontal como higiene bucal deficiente, presença de cálculo subgengival, inflamação intensa, morfologia irregular da margem gengival, mucosa eritematosa e sangramento espontâneo.

- Tanerella forsythensis - Invade células epiteliais e induz a morte celular por apoptose ${ }^{8}$;

Essas bactérias também têm sido identificadas em infecções extrabucais (Quadro 1).

Quadro 1 - Infecções Sistêmicas Causadas por Microrganismos Bucais *

\begin{tabular}{|c|c|}
\hline Infecções & Microrganismos \\
\hline \multirow[t]{4}{*}{ Endocardite infecciosa } & Estreptococos bucais \\
\hline & E. corrodens \\
\hline & A. actinomycetemcomitans \\
\hline & M. micros \\
\hline \multirow[t]{4}{*}{ Bacteremia } & Estreptococos bucais \\
\hline & P. gingivalis \\
\hline & Enterobacteriaceae \\
\hline & Cândida sp. \\
\hline Sepse & A. actinomycetemcomitans \\
\hline Abscesso cerebral & A. actinomycetemcomitans \\
\hline \multirow[t]{3}{*}{ Infecções respiratórias } & A. actinomycetemcomitans \\
\hline & Enterobacteriaceae \\
\hline & Staphylococcus \\
\hline Oftalmoplegia & A. actinomycetemcomitans \\
\hline Infecções intra-abdominais & P. gingivalis \\
\hline Otite média supurativa & P. gingivalis \\
\hline Infecções vaginais & M. micros \\
\hline Conjuntivite crônica & M. micros \\
\hline Endoftalmite & A. actinomycetemcomitans \\
\hline Abscesso do tubo ovariano & P. gingivalis \\
\hline
\end{tabular}

*Lotufo e Pannuti ${ }^{3}$ 
A doença periodontal é considerada como resultado de um processo interativo entre o biofilme e os tecidos periodontais por meio de respostas celulares e vasculares. Seu início e progressão envolvem um conjunto de eventos imunopatológicos e inflamatórios, com a participação de fatores modificadores locais, sistêmicos, ambientais e genéticos ${ }^{9}$.

Apesar do longo caminho que as pesquisas têm para percorrer, esta nova compreensão da periodontia já permite integrar a periodontopatia ao elenco de causas relacionadas a doenças capazes de levar o paciente ao óbito. Além disso, oferecem condições de suspeitar que as doenças periodontais e as sistêmicas apresentem relações diretas e bidirecionais, gerando necessidade no envolvimento das especialidades da área de saúde, para devolver o equilíbrio a essa unidade sóciobiológica indivisível, o ser humano.

\section{MICROBIOTA BUCAL}

Todas as superfícies do corpo humano são continuamente expostas à colonização por grande variedade de microrganismos que geralmente vivem em harmonia com o hospedeiro. Contudo, a descamação fisiológica que ocorre nas superfícies impede que se acumule grande quantidade de microrganismos ${ }^{10}$.

A boca também sofre contínua colonização apresentando uma vasta microbiota. Nela se encontra praticamente a metade da microbiota presente no corpo humano, representada por várias espécies de bactérias, fungos e vírus ${ }^{3}$. Entretanto, no ambiente bucal, são encontradas superfícies duras, não descamativas, como esmalte, cemento, próteses, entre outros, que favorecem o desenvolvimento de grandes depósitos de microrganismos, denominados placa bacteriana ${ }^{10}$. A placa, através das bactérias e de seu metabolismo, demonstrou ser capaz de produzir elementos irritantes como ácidos, endotoxinas e antígenos que, com o tempo, dissolvem os dentes e destroem os tecidos de suporte ${ }^{9,10}$, por isto é considerado o principal motivo para o estabelecimento da cárie, doença periodontal de infecções preiimplantares e de estomatites ${ }^{10}$. Além disso, a placa bacteriana pode servir de reservatório permanente de microrganismos, ocasionando infecção à distância como relatado na literatura ${ }^{11}$.

No contexto bucal, a placa bacteriana representa um biofilme verdadeiro, pois consiste de bactérias em matriz composta principalmente de polímeros extracelulares de origem bacteriana e produtos do exsudato do sulco gengival e/ou saliva ${ }^{10}$. $\mathrm{O}$ acúmulo bacteriano na boca será denominado biofilme (Figura 2).

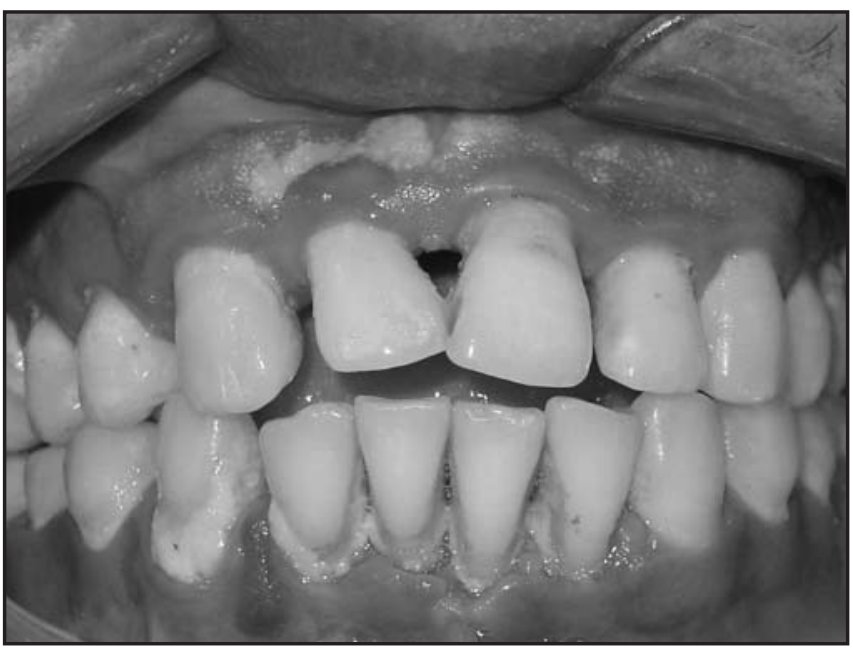

Figura 2 - Depósitos de Biofilme na Mucosa, Gengiva e Dentes

O biofilme forma-se virtualmente sobre as superfícies imersas em meio aquoso, natural e, particularmente de maneira rápida em sistemas fluidos em que fonte regular de nutrientes é fornecida às bactérias ${ }^{10}$. Além disso, o biofilme fornece às bactérias proteção, inclusive contra agentes antimicrobianos ${ }^{9,10}$.

A microbiota bucal sofre influência de fatores externos (tabagismo, alcoolismo, antibioticoterapia ou corticoterapia, permanência em ambientes hospitalares, estado nutricional e higiene bucal) e intrínsecos ao paciente (idade), pela possibilidade de alterar a imunidade local e a sistêmica e, por selecionar espécies bacterianas ${ }^{4}$.

\section{DOENÇAS PERIODONTAL E SISTÊMICA}

Dentre as doenças sistêmicas, as que acumulam mais evidências científicas da sua relação com as periodontais, são as doenças respiratórias. Vários estudos indicam que as periodontopatias podem influenciar o curso das infecções respiratórias destacando-se as pneumonias ${ }^{11}$.

A pneumonia é uma infecção debilitante, em especial, no paciente idoso e imunocomprometido. Nos hospitais, a pneumonia nosocomial exige atenção especial. É a segunda causa de infecção hospitalar; e, a responsável por taxas significativas de morbidade e mortalidade em pacientes de todas as idades ${ }^{11-14}$. Engloba de $10 \%$ a $15 \%$ das infecções hospitalares, sendo que de $20 \%$ a $50 \%$ dos pacientes afetados por este tipo de pneumonia falecem ${ }^{11,14}$. Os pacientes mais vulneráveis 
a esta importante infecção são os internados em unidades de terapia intensiva (UTI) ${ }^{12-15}$, em especial os que estão sob ventilação mecânica ${ }^{12,15}$, acometendo $20 \%$ a $25 \%$ destes pacientes, com as taxas de mortalidade podendo chegar em até $80 \%{ }^{12,14,16}$.

O estabelecimento da pneumonia nosocomial ocorre com a invasão bacteriana, especialmente bastonetes Gram-negativos (Acinetobacter spp., Staphylococcus aureus, Esherihia coli, Klebsiella spp, Pseudomonas aeruginosa, Enterobacter spp. e Proteus mirabiis ${ }^{14-16}$, no trato respiratório inferior por meio da aspiração de secreção presente na orofaringe, por inalação de aerossóis contaminados ou, menos freqüentemente, por disseminação hematogênica originada de um foco à distância ${ }^{12,13}$. Na literatura, dois casos foram relatados demonstrando que a difusão hematogênica ocorreu devido ao grande número de bactérias provenientes de infecção periodontal ${ }^{11}$. Porém, o meio mais comum de adquirir a doença é através da aspiração do conteúdo presente na orofaringe ${ }^{12,13}$.

A Medicina vem travando uma dura batalha contra a pneumonia nosocomial, pois além de causar números significativos de óbito e considerável sofrimento na raça humana ${ }^{11}$, provoca impacto expressivo aos custos hospitalares, pois pode atuar como fator secundário complicador prorrogando, em média de 7 a 9 dias, a hospitalização. Em pacientes intubados, a estada hospitalar pode ser prolongada em média entre 10 a 13 dias ${ }^{11-13} \mathrm{com}$ aumento significativo nos custos com diagnóstico e tratamento dessa infecção ${ }^{11,13}$.

Desta maneira, é imprescindível a realização de pesquisas para aperfeiçoar métodos de diagnóstico, tratamento e medidas eficazes para sua prevenção. A Odontologia deve se unir à Medicina em busca de resultados positivos para diminuir a pneumonia, uma vez que a forma mais comum de adquiri-la é por meio da aspiração do conteúdo da boca e da faringe ${ }^{11-13}$. E os estudos demonstram que $45 \%$ de adultos sadios e $70 \%$ de pacientes com depressão do nível de consciência apresentam aspiração de secreção da orofaringe durante o sono ${ }^{12,13}$.

\section{UNIDADE DE TERAPIA INTENSIVA}

Em UTI, a monitorização dos órgãos e sistemas, que não são a causa direta do problema que levou o paciente a essa condição, não deve ser esquecido. Esta atenção evita a deterioração de outro órgão ou sistema que pode contribuir para um prognóstico desfavorável do caso ${ }^{17}$. Isto inclui também o sistema estomatognático que deve receber a devida atenção. Uma vez que a prevalência, extensão e gravidade das doenças periodontais é muito alta na população ${ }^{18}$. Higiene bucal deficiente é um achado característico nos pacientes de UTI'11.

Estudos recentes mostraram que a quantidade de biofilme em pacientes de UTI, aumenta com o tempo de internação, paralelamente também ocorrem aumentos de patógenos respiratórios que colonizam o biofilme bucal ${ }^{11,14}$ (Figura 3). Lembrando que os patógenos respiratórios, que se estabelecem no biofilme, são mais difíceis de serem debelados, pois o biofilme propicia uma proteção às bactérias, tornado-as mais resistentes aos antibióticos do que às bactérias planctônicas ${ }^{11}$. Deve-se ressaltar que paciente com alteração do nível de consciência, condição comum UTI, aspira maior quantidade de secreção da boca com maior freqüência ${ }^{12,13}$.

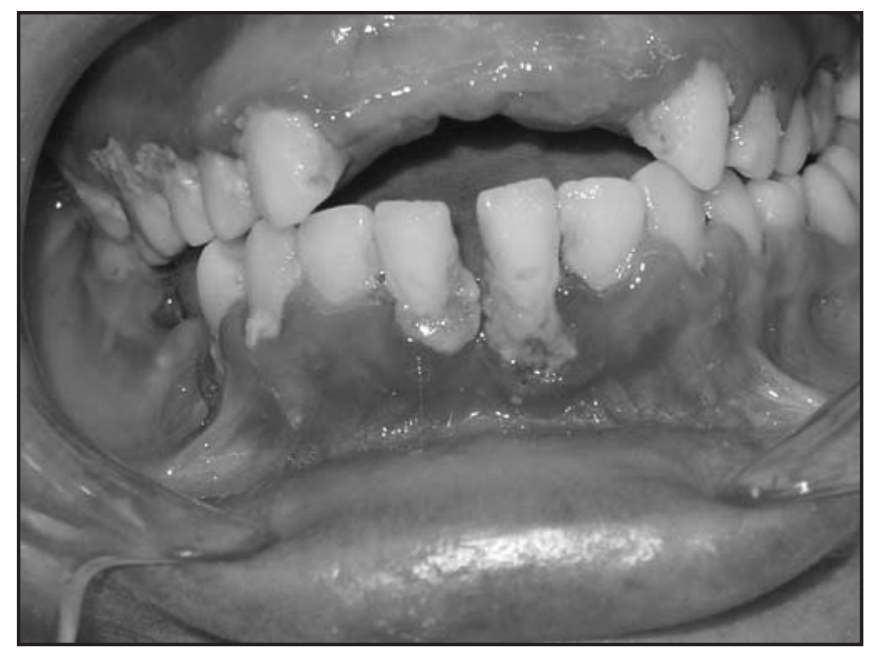

Figura 3 - Condição Bucal de Paciente Internado 12 Dias na UTI

Desenvolveu pneumonia nosocomial evoluindo para óbito.

Freqüentemente, em UTI o paciente necessita de ventilação mecânica. A literatura demonstra que as pneumonias associadas a este tipo de recurso acometem grande percentagem destes pacientes, com taxas alarmantes de mortalidade ${ }^{14}$. A colonização da orofaringe por microrganismos Gram-negativos, de pacientes intubados, ocorre nas primeiras 48 a 72 horas após a admissão na UTI, e alcançam os pulmões através das secreções bucais que "vazam" pelos lados do balonete do tubo traqueal ${ }^{14}$ (Figura 4). 


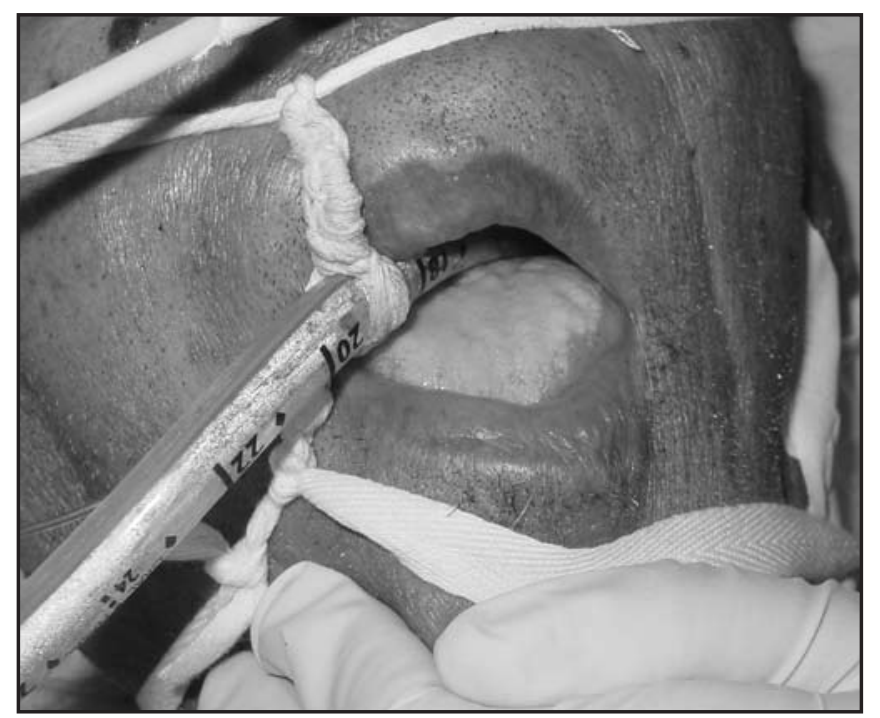

Figura 4 - Paciente Submetido à Ventilação Artificial apresentando Saburra Lingual Intensa.

\section{ATUAÇÃO DO CIRURGIÃO-DENTISTA EM UTI}

Até então, o obstáculo freqüentemente enfrentado pelo cirurgião-dentista para integrar equipes multidisciplinares em UTI, estava com baixa prioridade do procedimento odontológico diante dos numerosos problemas apresentados pelo paciente. Entretanto, a literatura tem demonstrado, de maneira clara e vigorosa, a influência da condição bucal na evolução do quadro dos pacientes internados.

Estudos indicam que pacientes de UTI apresentam higiene bucal deficiente, com quantidade significativamente maior de biofilme do que indivíduos que vivem integrados na sociedade. Também se pode observar nesses pacientes, maior colonização do biofilme bucal por patógenos respiratórios ${ }^{19,20}$. Sendo que, a quantidade e a complexidade do biofilme bucal aumenta com o tempo de internação ${ }^{21}$. Estes resultados levam tais estudos a sugerir que a colonização do biofilme bucal por patógenos, em especial os respiratórios, pode ser uma fonte específica de infecção nosocomial importante em UTI. Uma vez que as bactérias presentes na boca podem ser aspiradas e causar pneumonias de aspiração ${ }^{11}$.

O valor dos cuidados com a saúde bucal na prevenção da pneumonia é evidente. As pesquisas científicas que analisam grupo tratado e grupo controle, com parâmetros de risco similares para infecção, demonstraram diminuição significativa na incidência de pneumonias, no uso de antibióticos não profiláticos e redução nas taxas de mortalidade no grupo submetido à atenção odontológica $^{6,7}$ (Figuras 5 e 6).

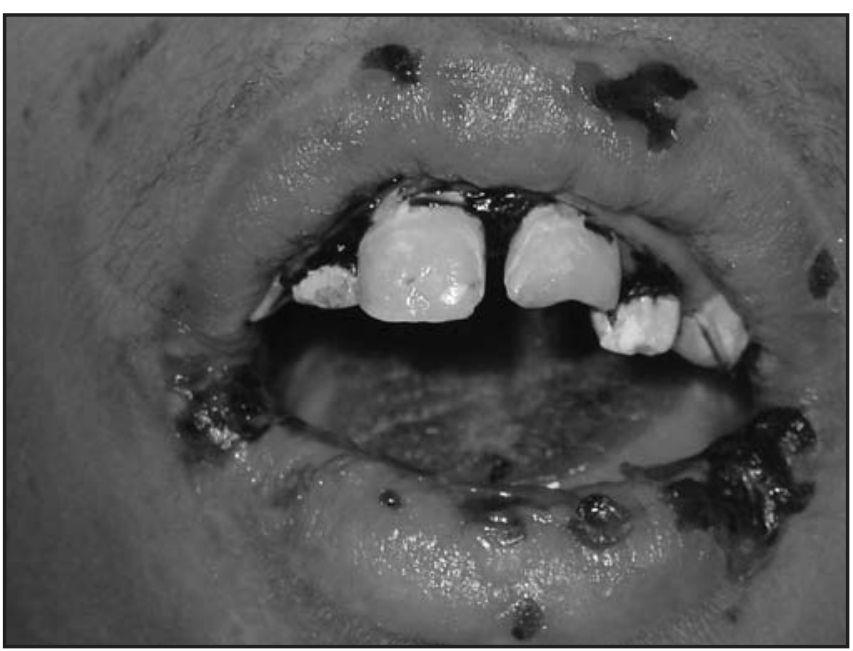

Figura 5 - Paciente Politraumatizado, Inconsciente (5 dias na UTI)

Nota-se a presença de quantidade significativa de biofilme por toda a boca, úlceras labiais e sangramento.

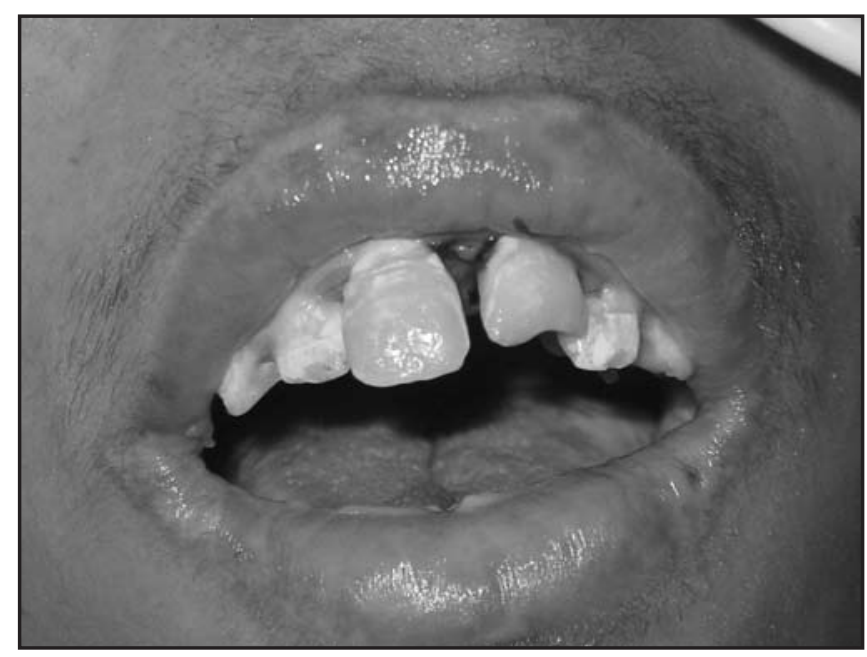

Figura 6 - Condição Bucal após Dois Dias Recebendo Acompanhamento Odontológico.

Nota-se redução importante na quantidade de biofilme bucal, melhora significativa das úlceras labiais e do sangramento.

Em vista de dados de fisiopatologia mostrando possível relação entre cuidados odontológicos e pneumonias nosocomiais, o Cirurgião-Dentista poderia acrescentar-se à equipe multiprofissional em benefício do paciente crítico. Uma vez que a higiene bucal deficiente e a presença de doença periodontal no paciente de UTI, sem dúvida constituem-se em mais um fator que pode favorecer o desenvolvimento de pneumonia nosocomial. Primeiro, porque esta condição bucal resultaria 
em alta concentração de patógenos na saliva podendo ser aspirado para o pulmão em abundância, Segundo, o biofilme bucal pode abrigar patógenos pulmonares e promover seu crescimento. E, por fim, os patógenos periodontais poderiam facilitar a colonização das vias aéreas superiores por patógenos pulmonares.

\section{REFERÊNCIAS}

01. Reilly PG, Glaffey NM - História da Sepsia Bucal como Causa de Doenças, em: Williams RC, Offenbacher S - Periodontologia 2000. São Paulo: Santos, 2005;13-18.

02. Cohen DW - Relação de Risco Médico-Periodontal, em: Cohen DW Aspectos Periodontais da Saúde Sistêmica. Compendium of Continuing Education in Dentistry. 1998;19:11-24.

03. Lotufo RFM, Pannuti CM - Efeitos Diretos dos Patógenos Bucais nas Condições Sistêmicas, em: Brunetti MC - Periodontia Médica. São Paulo: SENAC, 2004;42-57.

04. Misiara ACO - Considerações Médicas sobre Pacientes com Problemas Respiratórios, em: Brunetti MC - Periodontia Médica. São Paulo: SENAC, 2004;375-390.

05. Williams RC, Paquette D - Periodontite como Fator de Risco para Doença Sistêmica, em: Lindhe J, Karring T, Lang NP - Tratado de Periodontia Clínica e Implantologia Oral. 4ª Ed, Rio de Janeiro: Guanabara Koogan, 2005;356-375.

06. DeRiso AJ, Ladowski JS, Dillon TA et al - Chlorhexidine gluconate $0.12 \%$ oral rinse reduces the incidence of total nosocomial respiratory infection and nonprophylactic systemic antibiotic use in patients undergoing heart surgery. Chest, 1996;109:1556-1561.

07. Yoneyama T, Yoshida M, Ohrui T et al - Oral care reduces pneumonia in older patients in nursing homes. J Am Geriatr Soc. 2002;50:430:433.

08. Socransky SS, Haffajee AD - Microbiologia da Doença Periodontal, em: Lindhe J, Karring T, Lang NP - Tratado de Periodontia Clínica e Implantologia Oral. $4^{\text {a }}$ Ed, Rio de Janeiro: Guanabara Koogan, 2005;105-147.
09. Sallum AW, Martins AG, Sallum EA - A Doença Periodontal e o Surgimento de um Novo Paradigma, em: Brunetti MC - Periodontia Médica. São Paulo: SENAC, 2004;20-39.

10. Lang NP, Mombelli A, Attstrom R - Placa e Cálculo Dental, em: Lindhe J, Karring T, Lang NP - Tratado de Periodontia Clínica e Implantologia Oral. $4^{a}$ Ed, Rio de Janeiro: Guanabara Koogan; 2005;80-104.

11. Sannapieco FA - Relação entre Doença Periodontal e Doenças Respiratórias, em: Rose LE, Genco RJ, Mealy BL et al - Medicina Periodontal. São Paulo: Santos, 2002;83-97.

12. Consenso Brasileiro de Pneumonias em Indivíduos Adultos Imunocompetentes. J Pneumol, 2001;27:(Suppl1):S22-S40.

13. Fourrier F, Duvivier B, Boutigny $\mathrm{H}$ et al - Colonization of dental plaque: a source of nosocomial infections in intensive care unit patients. Crit Care Med, 1998;26:301-308.

14. Scannapieco FA, Rossa Júnior C - Doenças Periodontais versus Doenças Respiratórias, em: - Brunetti MC - Periodontia Médica. São Paulo: SENAC, 2004;391-409.

15. Nakatani J, Rocha RT - Pneumonia Adquirida na Comunidade e no Hospital, em: Prado FC, Ramos J, Valle JR - Atualização Terapêutica. 21ª Ed, São Paulo: Artes Médicas, 2003;1453-1461.

16. Rothman A, Barbas CSV, Camargo LFA - Infecções Respiratórias em

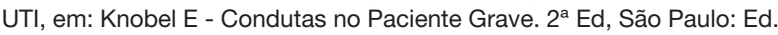
Atheneu, 1999;771-780.

17. Sampliner JE - Cuidados Gerais com Paciente em Estado Crítico, em: Berk JL, Sampliner JE - Manual de Tratamento Intensivo. $2^{\text {a }}$ Ed, Rio de Janeiro: Medsi, 1983;33-44.

18. Oppermann RV, Susin C, Cortelli SC et al - Epidemiologia das Doenças Periodontais. Rev Periodontia, 2005;15:63-76.

19. Russell SL, Boylan RJ, Kaslick RS et al - Respiratory pathogen colonization of the dental plaque of institutionalized elders. Spec Care Dentist. 1999;19:128-134.

20. Scannapieco FA, Stewart EM, Mylotte JM - Colonization of dental plaque by respiratory pathogens in medical intensive care patients. Crit Care Med, 1992;20:740-745.

21. Fernandes AT, Zamorano PO, Torezan Filho MA - Pneumonia Hospitalar, em: Fernandes AT, Fernandes MOV, Ribeiro Filho N - Infecção Hospitalar e suas Interfaces na Área da Saúde. São Paulo: Atheneu, 2000;516-555. 